decreased intermeal intervals are also seen (Le Magnen \& Tallon, 1968). The present results demonstrate that such attenuation of satiety by insulin does not require repeated experience of the effects of the hormone, which might allow conditioning or instrumental learning (Le Magnen, 1956; Booth, Goodchild, \& Lovett, 1968; Lovett \& Booth, 1970) to contribute to the changes in the observed meal patterns (Le Magnen \& Tallon, 1967). Differences between this last report and the present results may also arise from different effects of injected insulin on daytime and nightime metabolism and feeding (Le Magnen \& Davos, 1969).

\section{REFERENCES}

BOOTH, D. A., \& BROOKOVER, T. Hunger elicited in the rat by a single injection of bovine crystalline insulin. Physiology \& Behavior, 1968, 3, 447-453.

BOOTH, D. A., GOODCHILD, P., \& LOVETT, D. Depression of intake of nutrient by association of its odor with effects of insulin. Psychonomic Science, 1968, 11, 27-28.

LE MAGNEN, J. Le rôle des stimulations olfacto-gustative dans les mecanismes de regulation de la prise alimentaire. Annales de la Nutrition et l'Alimentation, 1956, 10, 153-158.

LE MAGNEN, J., \& DAVOS, M. Le substrat metabolique de la faim. Comptes Rendus de l'Académie des Sciences, 1969, 268, 3107-3110.

LE MAGNEN, J., \& TALlON; S. Effet des administrations d'insuline et de thyroxine sur la fréquence at l'amplitude unitaire des prises d'aliments chez le rat. Comptes Rendus de la Societé de Biologie (Paris), 1967, 161, 1303-1306.

LE MAGNEN, J., \& TALLON, S. L'effect du jeune prealable sur les caracteristiques temporelles de la prise d'aliments chez le rat. Journal de Physiologie (Paris), 1968, 60, 143-154.

LOVETT, D., \& BOOTH, D. A. Four effects of exogenous insulin on food intake. Quarterly Journal of Experimental Psychology, 1970, 22 , in press.

\title{
An effect of flavors on strength of conditioned aversions*
}

\section{KENNETH F. GREEN and PEGGY ANN CHURCHILL \\ California State College, Long Beach, Calif. 90801}

Attempts to condition aversions to nonpreferred flavors have not been as consistently successful as when preferred flavors were used. To find if the problem is one of method of measurement or if it is a general characteristic in the conditioning of aversions, the present experiment used several measurement procedures to compare aversions formed by rats to one preferred and one nonpreferred flavor. On all measures, whether relative (decreases in intake) or absolute (final amount consumed), aversions for the preferred flavor were greater than for the nonpreferred flavor.

Conditioned aversions to flavors occur when rats sample a flavored substance (CS) and subsequently become ill (US). Most experimentation on the phenomenon has used fluids that are preferred to water as CSs on the assumption that it is harder to condition an aversion to a preferred stimulus than to a nonpreferred stimulus, and thus a more convincing demonstration of an aversion can be obtained if contact with the CS decreases from a high level than if it decreases from a low level.

Results of studies using nonpreferred CSs have not been entirely consistent with one another. With hydrochloric acid or quinine solutions, Garcia, Green, \& McGowan (1969) reported strong conditioned aversions. With grape juice, Green (1969) reported strong aversions, Revusky \& Bedarf (1967) reported weak aversions, and Wittlin \& Brookshire (1968) reported no aversions. The latter pairs of Es tested for aversions by pairing grape juice with milk, a preferred substance, in a two-bottle test and comparing intake of

*This work was supported in part by a grant from the Long Beach California State College Foundation. experimental rats to intake of controls; by contrast, the former Es either used a single-flavor testing procedure or a two-flavor procedure where both flavors were nonpreferred. In the case where a nonpreferred CS was paired with a preferred comparison flavor, a floor effect might have prevented aversions from being shown. Alternatively, the highly sensitive two-bottle test might have emphasized a basic difficulty in conditioning aversions to nonpreferred CSs: Preference value of a CS might be inversely related to strength of conditioned aversions. Since no major theory of learning suggests such a relationship, the variable of CS preferability was examined in a situation where the possible artifact of a floor effect could be accounted for. The present experiment therefore provided direct comparisons between aversions formed to preferred and nonpreferred CSs and measured the aversions with one-flavor and two-flavor test methods.

\section{METHOD}

Ten female albino rats from the Psychology Department breeding colony weighed $200-250 \mathrm{~g}$ at the start of the experiment. They were given 10 days to adjust to a schedule of $20 \mathrm{~min}$ of drinking per day, with tap water given between the hours of 11 and $12 \mathrm{a} . \mathrm{m}$. as part of a maintenance routine that included feeding, handling, and weighing of bottles to the nearest 0.1 g. On Day 11 , a neophobia day, grape juice (Welch's unsweetened) alone was given. Day 12 was a water day. On Day 13 all rats were given a neophobia day with milk (Pet evaporated, mixed with an equal volume of tap water) alone. Day 14 was a water day, Day 15 was a single-flavor pretest day with milk presented alone, Day 16 was a water day, Day 17 was a single-flavor pretest day with grape juice alone, and Day 18 was a water day. On Days 19 and 20, two-bottle pretests were given with grape juice presented on the left-hand side of the rats' cages immediately before milk was presented on the right. Separate sets of glass bottles, rubber stoppers, and metal spouts were used for each fluid, and each rat was assigned its own bottle-stopper-spout combination for each flavor. Fluids were always presented at room temperature. Acquisition began on Day 20 and consisted of five blocks of 3 days: The 1st was a conditioning day and the remaining 2 were water days. On conditioning days, five rats were given grape juice and the remaining five rats were given milk. Five minutes after fluid presentation, the rats were injected intraperitoneally with apomorphine hydrochloride $(18 \mathrm{mg} / \mathrm{kg}$, mixed in sterile water $12 \mathrm{mg} / \mathrm{ml}$ ), and the fluids were removed after the rats stopped drinking, which invariably occurred within 2 min of injection. Posttests consisted of 2 consecutive days of two-bottle testing, executed as described above, and 2 days of single-bottle testing, given with grape juice and then milk, and with a water day preceding each flavor day.

\section{RESULTS}

All rats increased their intake of each flavor from the neophobia day to the single-bottle pretest day. Figure 1 presents the mean intakes of the CS fluids by the two groups in the single-bottle pretest and posttest in the two-bottle pretest and posttest (the intakes on the pairs of days were averaged together) and during acquisition. In the figure and in the material to follow, the amounts consumed by a group refer to the flavor used as the CS for that group.

In the single-bottle test, pretest intake of all milk rats (mean, $12.8 \mathrm{~g}$ ) was greater than intake of all grape juice rats $(8.2 \mathrm{~g})$; all rats decreased their intake from pretest to posttest, with all milk rats but one declining $(9.6 \mathrm{~g})$ more than all grape juice rats $(3.7 \mathrm{~g})(\mathrm{U}=1, \mathrm{p}<.01)$; in the posttest 


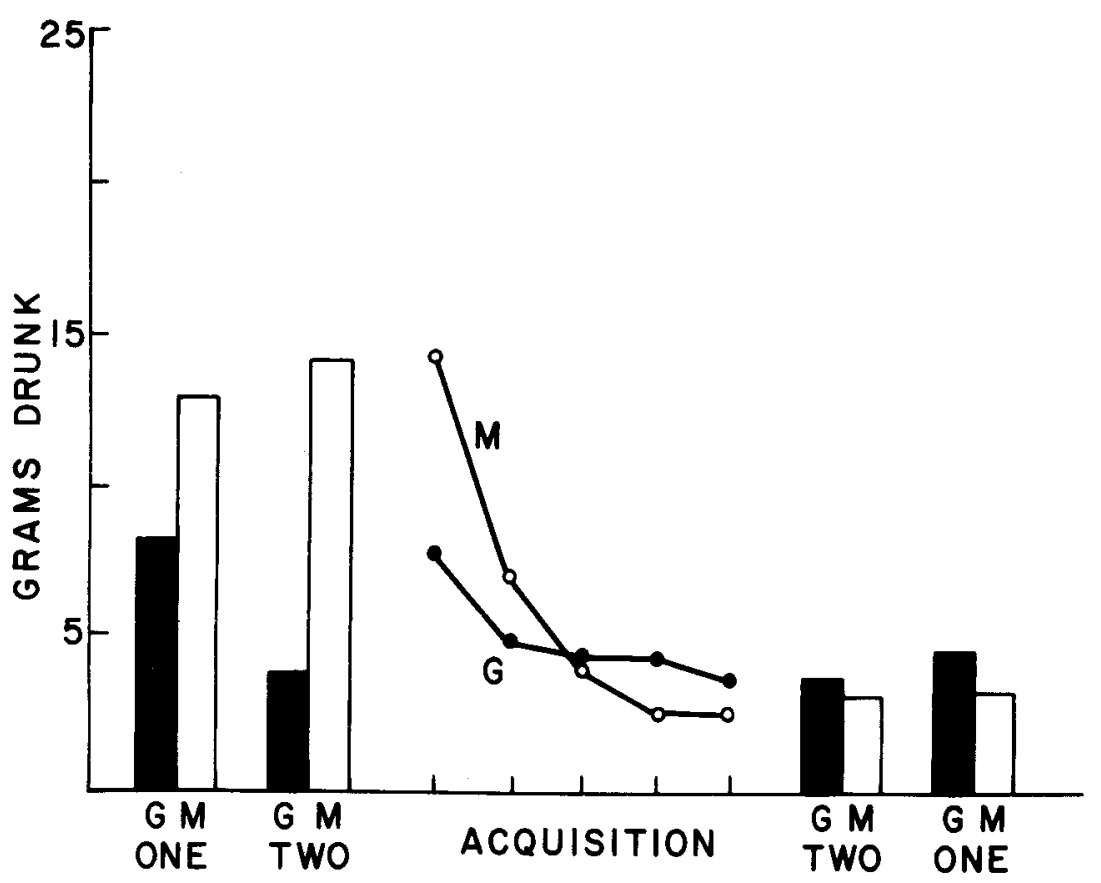

Fig. 1. Mean intake of grape juice $(G)$ by the rats drinking grape juice prior to illness and of milk (M) by the rats drinking milk prior to illness. ONE = single-bottle test; TWO $=$ two-bottle test. Intake during acquisition was of the indicated flavor presented alone.

the intake of all milk rats $(3.2 \mathrm{~g})$ was lower than the intake of all grape juice rats $(4.5 \mathrm{~g})$.

In the two-bottle tests, pretest intake of all milk rats $(14.3 \mathrm{~g})$ was greater than pretest intake of all grape juice rats $(3.7 \mathrm{~g})$; all milk rats decreased their intake from pretest to posttest $(11.6 \mathrm{~g})$, while the grape juice rats did not change $(0.1 \mathrm{~g})$; the posttest intake of the highest milk rat was equal to the posttest intake of the lowest grape juice rat $(\mathrm{U}=1, \mathrm{p}<.01)$.

In acquisition, all milk rats began at a higher level $(14.3 \mathrm{~g})$ than did the grape juice rats $(7.9 \mathrm{~g})$; all milk rats declined more than did all grape juice rats $(11.7$ vs $4.3 \mathrm{~g}$ ); on the 4 th conditioning day all milk rats drank less than did all grape juice rats ( 2.5 vs $4.3 \mathrm{~g}$ ); but on the 5 th conditioning day two grape juice intakes entered the distribution of milk intakes and prevented statistical significance from being achieved.

\section{DISCUSSION}

All measures were consistent in indicating a stronger aversion to the preferred CS than to the nonpreferred CS. In all tests the initial intake of milk exceeded the initial intake of grape juice, thus confirming the relative preference values of the two flavors. In all tests, milk showed a greater decrease than did grape juice. This effect was especially impressive in the two-bottle test, where the grape juice rats failed to show their aversion altogether, a result identical to that reported by Wittlin \& Brookshire (1968). In all tests milk reached a lower absolute level than did grape juice. Again, this effect was most impressive in the two-bottle test, for the fact that the milk rats drank less than did the grape juice rats indicates that it was not a floor effect that prevented the grape juice rats' aversion from manifesting itself. Finally, the lack of overlap between flavor groups on most measures testifies to the consistency of the effect of the CS.

It could be argued that the rats formed stronger aversions to milk because they initially drank large amounts of it. This suggestion may be discounted because Revusky \& Bedarf (1967) obtained strong aversions to milk in rats given only 100 licks of exposure to it, and our experience with drinkometers indicates that 100 licks yield less than half the lowest amount drunk by any grape juice rat $(2.5 \mathrm{~g})$ in the present experiment.

It could be argued that milk tasted more distinctively different from every day water than did grape juice, and that this difference could account for the present results (Kimble, 1961, p. 122). To the human taster, this judgment proved exceedingly difficult, so it might be argued in return that the two flavors were about equally different from water. More substantially, Rozin (1969) found little difference in aversion strength between groups conditioned to a high-conce., iration CS and groups conditioned to a low-concentration CS. Thus, the distinctiveness variable does not appear to be responsible for the present results.

Other interpretations might be offered in terms of disparity of CS and US, such that the effectiveness of a CS increases as its attractiveness diverges from that of the US, or in terms of CS attractiveness, such that conditioning occurs more readily with a more attractive $C S$, regardless of the nature of the US. A choice between these interpretations cannot be made on the basis of the present data. However, an approach response to a positive US would allow a choice because the disparity hypothesis would predict more rapid learning with a nonpreferred $C S$, while the attractiveness hypothesis would predict more rapid learning with a preferred CS

Since this paper was submitted, Kalat \& Rozin (1970) have reported that some flavors can affect aversion strength more readily than others. Specifically, on the basis of amount consumed in a two-bottle test given the day after a single conditioning trial, they were able to rank the aversiveness of their four flavors, from most aversive to least, as casein hydrolysate, sucrose, salt, and vanilla. Control rats ranked the flavors on palatability, from greatest intake to least, as sucrose, salt, vanilla, and casein hydrolysate. Since casein hydrolysate was least preferred and became most aversive, it deviates widely from the CS attractiveness notion, yet it should be noted that the remaining flavors were consistent with the notion. The Kalat and Rozin data detract from the proposed CS attractiveness role inasmuch as other factors, perhaps intensity of flavor, ease of digestion, specific food value, or some other factor, may override it.

\section{REFERENCES}

GARCIA, J., GREEN, K. F., \& McGOWAN, B. K. X-ray as an olfactory stimulus. In $C$. Pfaffman (Ed.), Olfaction and taste III. New York: Rockefeller University Press, 1969. Pp. 299-309.

GREEN, K. F. Aversions to grape juice induced by apomorphine. Psychonomic Science, 1969, 17, 168-169.

KALAT, J. W., \& ROZIN, P. "Salience": A factor which can override temporal contiguity in taste-aversion leavening. Journal of Comparative \& Physiological Psychology, 1970, 71, 192-197.

KIMBLE, G. A. Hilgard \& Marquis's Conditioning and learning. $\quad \mathrm{New} \quad \mathrm{Y}$ ork: Appleton-Century-Crofts, 1961.

REVUSKY, S. H., \& BEDARF, E. W. Association of illness with prior ingestion of novel foods. Science, 1967, 155, 219-220.

ROZIN, P. Central or peripheral mediation of learning with long CS-UCS intervals in the feeding system. Journal of Comparative \& Physiological Psychology, 1969, 67, 421-429.

WITTLIN, W. A., \& BROOKSHIRE, K. B. Apomorphine-induced conditioned aversions to a novel food. Psychonomic Science, 1968 , 12, 217-218. 